\title{
A Discussion on the Training of Literature Retrieval and Integrated Utilization Ability of Graduate Students in Local Universities
}

\author{
Yongchun Piao \\ Normal College \\ Yanbian University \\ Yanji, China \\ 1154797729@qq.com
}

\author{
Corresponding author: Xue-mei Cui* \\ Normal College \\ Yanbian University \\ Yanji, China \\ xmcui@ybu.edu.cn
}

\begin{abstract}
-literature retrieval and integrated utilization is an important guarantee for graduate students' ability of Scientific Research and Innovation, so the ability of retrieval and integrated utilization should be cultivated throughout the postgraduate education. Based on the literature rese arch me thod, this research analyzes the problems in the literature retrieval and integrated utilization of graduate students in local universities, and propose a frame to develop the literature retrieval and integrated utilization ability of graduate students in four aspects including the understanding of literature retrieval and utilization ability, the channels and management tools of literature retrieval, the teaching in the class of literature retrieval and utilization ability, the related training of literature retrieval and utilization. This research provides a useful reference for the promotion of the integrative quality of the graduate students.
\end{abstract}

Keywords-local universities; graduate students; literature retrieval ability; integrated utilization ability

\section{INTRODUCTION}

Literature retrieval is a simple way for researchers to quickly find problems and enter the frontier of research. It's also a basic skill which all researchers must master. As a graduate student, literature retrieval is of great significance. It plays an important role in orienting research direction, setting research topics, research plans and research programs. Literature retrieval can also help to conduct research and analyze, discuss the results of research. Therefore, collecting and mastering a large number of cutting-edge literatures are necessary conditions for graduate students to engage in scientific research, integrated utilization of literatures is a necessary prerequisite for effective high-quality scientific research.

In china, local universities account for more than $90 \%$ of total, which compose the main part of higher education. Therefore, information retrieval ability and integrated utilization ability of graduate students in local universities are very important to the cultivation of graduate students' innovation ability and scientific research ability.

Based on the literature research method, this research analyzes the problems in the literature retrieval and integrated

This research was supported by the high education research project of Jilin association of higher education in 2016(Grant No. 2016[9]) and was also supported by the excellent graduate course of Yanbian university in 2017 ("education measurement and evaluation theory and practice"). utilization of graduate students in local universities, and proposes a frame to develop the literature retrieval and integrated utilization ability of graduate students.

II. THE PROBLEMS IN THE LITERATURE RETRIEVAL AND INTEGRATED UTILIZATION OF GRADUATE STUDENTS IN LOCAL UNIVERSITIES

In the second half of 2014, 386 questionnaires from university libraries in 30 provinces and municipalities [1] were carried out. The condition of postgraduate literature retrieval and utilization class is shown in Fig. 1. The training condition of literature retrieval and utilization of graduate students is shown in Fig. 2.

Based on the survey above, we analyze the problems which exist in the literature retrieval and integrated utilization of postgraduate students in local universities.

\section{A. Lack of understanding the importance of literature}

retrieval and utilization in scientific research innovation

As we can see in Fig. 1(a), the rate of postgraduate literature retrieval and utilization course is less than $35 \%$, and that $2 / 3$ of them is elective course, most of them only have about 18 teaching hours [2]. All of these matters root in that universities have not estimated the information retrieval and utilization ability of postgraduate students as a necessary skill, and universities also have not paid enough attention to the cultivation of literature retrieval and utilization ability.

For those students in the universities which offer the literature retrieval and utilization course, just a few of them learned the course during undergraduate stage. The irregular teaching capacity of teachers, the poor recognition of literature retrieval, the slow textbook contents development, the lack of course standardization, and the weak connection between theory and practice, all of these make the postgraduates can't implement retrieval methods in practice, and finally, postgraduates misunderstand literature retrieval and utilization as a dispensable skill in scientific research. 


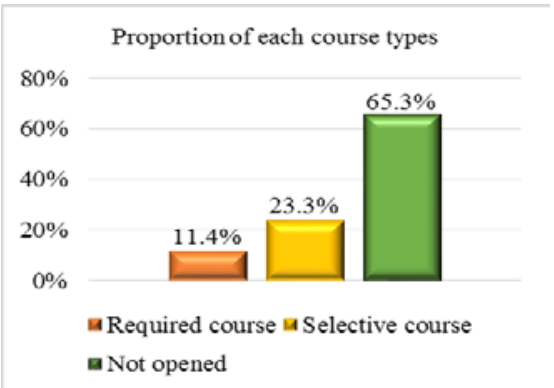

(a)

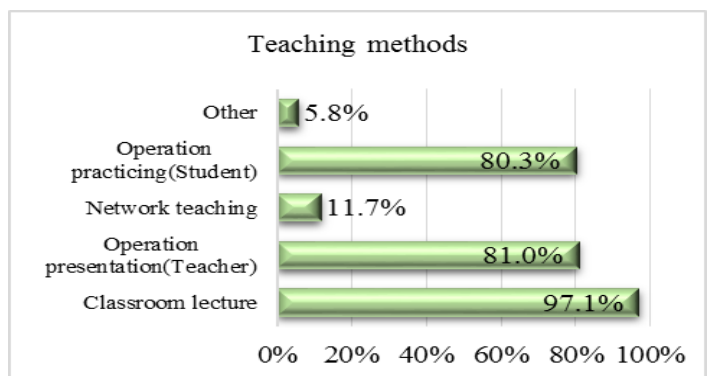

(b)

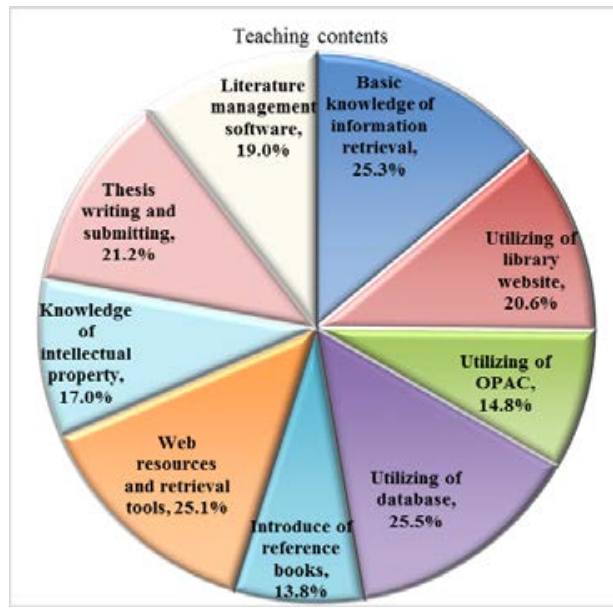

(c)

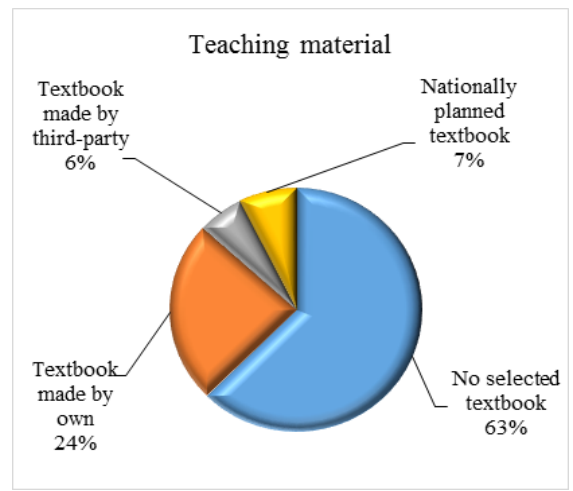

(d)

Fig. 1. Results of the survey of postgraduate literature retrieval and utilization class. (a)Proportion of each course type; (b) Proportion of each teaching method that used in course; (c) Proportion of each teaching content; (d)Condition of textbook selection.

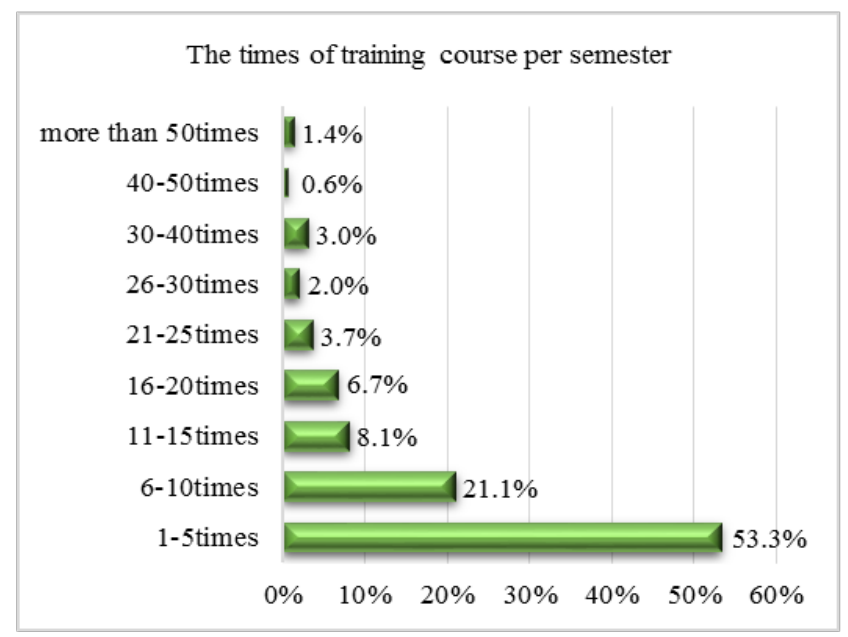

(a)

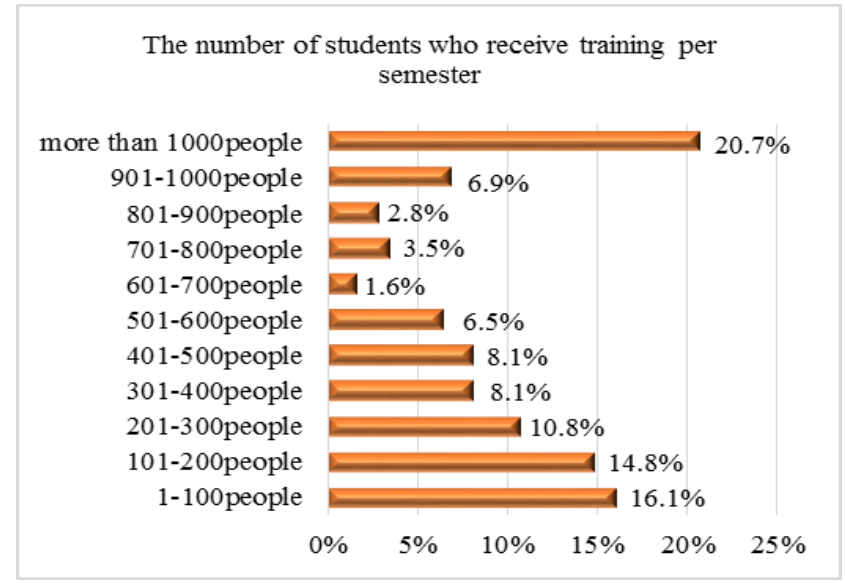

(b)

Fig. 2. Condition of the training of literature retrieval and utilization of graduate students. (a)The times of training course per semester; (b)The number of students who receive training per semester.

\section{B. The resources provided by universities are insufficient, literatures are difficult to collet.}

The collections in some central subordinate universities are very sufficient, and the vast literatures are easy to access. However, most local universities have limited books and ebooks due to the budget reasons. Most local universities have not got all the download right of Chinese and foreign literatures, bringing great difficulties to graduate students' literature retrieval. For example, our university has bought the download right of VIP, Wan Fang, CNKI, ScienceDirect, EBSCOHOST and KISS-the database of journals of Korean students, but they are still not enough, graduate students also need EI and ISTP to refer in scientific research.

\section{The role of literature retrieval and utilization course is not fully played.}

In February 1984, the Ministry of Education distributed "the opinion on the establishment of 'literature retrieval and Utilization' course”, the file pointed out that literature retrieval and utilization course not only contributes to the quality of teaching, but also plays a role as a component of future- 
oriented education. The course is of great significant for students to learn new knowledge, modify the knowledge structure, improve the ability of self-study and research, and play their creative talents. It will become a basic course which able to improve students' information processing capability and quality.

As the Fig. 1 (a)-(d) have shown to us, the overall course rate in China is no more than $35 \%$ when it is $42 \%$ in Beijing[3], it means that course rate all over the country is slightly low; The main teaching methods consists of classroom teaching, teachers' operation presentation and students' operation practicing, traditional teaching methods occupies the dominant position in the course; the main parts of teaching contents are traditional literature retrieval theory, utilization of database and retrieval skill training, but there are few of new theories, new techniques and new methods; most universities don't have designated textbooks for the course, the adoption of nationally planned textbooks is also rare.

These researches and related literatures [4-10] show that the condition of graduates' information retrieval and utilization course in local universities is terrible. There are such problems as low orientation of curriculum objectives, changeless teaching contents, poor combination of curriculum contents and professional learning, lack of first-class teachers, poor faculty, teaching materials and teaching contents unable to keep pace with new generation, etc.

\section{Few channels for graduate students to improve their literature retrieval and integrated utilization.}

From Fig. 2, we know that more than half of all universities organize trainings less than 5times each semester, and $40 \%$ universities train less than 300 people each semester. It means that the trainings in universities are far from completely meeting the students' need. In particular, there are many difficulties to develop high quality training in local universities due to various reasons such as geographical location, expert resources and so on.

\section{A FRAME TO CULTIVATE POSTGRADUATE LITERATURE RETRIEVAL AND INTEGRATED UTILIZATION ABILITY}

\section{A. Increase the awareness of literature retrieval and utilization ability training.}

At first, universities should be aware of that literature retrieval ability and literature integrated utilization ability have a deep impact on graduate students' innovation ability, actively launch the literature retrieval and utilization course, set course hour properly contingent on students' context, increase funding for curriculum implementation to provide enough hardware and software resources.

Secondly, supervisors should pay attention to the literature retrieval and integrated utilization ability of their students, completely understand the importance of the literature retrieval and integrated utilization ability, make a high requirement for students, create a good academic atmosphere, make students enter the specific field as soon as possible, and improve the quality of students' researches. Supervisors can cultivate students' literature retrieval ability mainly by introducing literature retrieval methods; teaching the selection of literature database and specialized database; training students' skills of skimming, reading, screening, analyzing; helping students to cultivate a good habit of literature reading. Only when graduate students have read a quiet amount of literatures, can they know domestic and abroad research status of their research fields, it can help them set the starting point of their research and avoid repeated research.

Finally, with the guidance of schools and tutors, graduates should realize the importance of literature retrieval and utilization ability in scientific research, and they should actively promote their ability of literature retrieval and comprehensive utilization under the consideration of their own research case.

\section{B. Guide graduate students to make full use of various channels to retrieve literature and learn to use literature management software.}

When a university doesn't have enough resources to meet the need of graduate students, these students still can get access to a target resource by various channels. They can get a database link with the help of their friends and net friends, they can also search the entry or abstract on Google or SCIRUS; with the interlibrary loan service like BALIS, CASHL, CALIS, they can get access to a document of other universities' library, the national library, the national science and technology library, students can also get access to an abroad literature by specialized search services; with some scientific websites like Xiao $\mathrm{Mu}$ Chong, students can get a literature or upload a literature in free.

After collecting the literatures, the graduate students need to read and integrate a large number of literatures, and literature management software is necessary in this stage. In recent years, there is much commonly used software in China, such as NoteExpress, NoteFirst, EndNote and so on. Such document management software can conveniently organize documents, search literatures, formulas and data. In addition, document management software plays an important role in the reference documents management in the writing of scientific paper and doctoral thesis.

\section{Improve the teaching efficiency of postgraduate literature retrieval and utilization course.}

The goal of literature retrieval and utilization course in graduate stage is to train students' information processing ability, strengthen the education of information concept. The goal should be in accordance with the demands of the knowledge economy generation and the information era.

The contents of literature retrieval and utilization course should consist of information awareness, information ability and information morality, so that the students can feel a strong sense of social responsibility and integrity scientific attitude. In addition, the contents of teaching should closely related to the development and change of new technologies and new information resources, so as to improve the efficiency of retrieval practice; course contents should closely integrated with professional courses to stimulate students' information demands and learning effectiveness. 
Design a new model of literature retrieval and utilization course. Reform the curriculum system, condense course contents, emphasize the training of application ability and autonomous learning ability; design a multi-level teaching structure for each stage like "orienting stage", "entry stage", "advanced stage"; introduce the teaching mode of the subject, through the analysis of the case study; make graduate students have a good ability of document retrieval, comprehensive management and utilization; make graduate students learn to read literatures, have the ability to make certain innovative subjects, write excellent scientific papers; introduce MOOC, micro-lectures, flipped classroom, MAKER to improve the postgraduates' ability of literature retrieval and integrated utilization, promote the personalized development of postgraduate's literature retrieval and utilization ability.

Pay more attention to improving the quality of the teaching staff in the literature retrieval and utilization. The teachers of the postgraduate literature retrieval and utilization course are mainly from the libraries in universities, most of them are parttime teachers. There are serious demands for universities to make more and better teachers.

It is urgent to strengthen the teaching materials construction of literature retrieval and utilization course in universities. They should compile textbooks for different professional characteristics; provide high-quality teaching resources.

\section{Local universities should cooperate with each other, actively carry out the related training of literature retrieval and utilization.}

Training seminar is an important channel for graduate students to understand academic frontiers, broaden their academic horizons and open up their research ideas. A good seminar can provide related resources, answer problem-solving, enlighten thinking, and share research results. Training seminar also can offer contents to literature retrieval and utilization course, improve the course efficiency. Local universities should cooperate with each other, share resources, and actively carry out the related training of literature retrieval and utilization, to finally achieve the goal of mutual reinforcement and mutual development.

\section{SUMMARY}

With the continuous development of network technology and information technology, the scope of literature retrieval is broader; the methods of retrieval are more flexible and diverse. The ability of literature retrieval and integrated utilization is very important for postgraduates to understand their research status and research frontiers in time, accurately grasp the trend of research and improve the level of scientific research, and it even can decide the quality of whole postgraduate education. To strengthen the literature retrieval and utilization ability, we should firstly understand what is the literature retrieval and utilization ability, and help students master the literature retrieval methods, set up the literature retrieval and utilization course, carry out the training of literature retrieval and utilization. All of these can help graduate students improve the awareness of information, master retrieval tools, improve the ability of integrate, process, analyze, review and utilize, improve students' independent working ability, thinking ability, innovation ability, and improve whole graduate education efficiency.

\section{REFERENCES}

[1] A survey of information literacy education in universities in China [EB/OL]. [2018-01-20]. http://www.sojump.com/viewstat/3788557.aspx.

[2] X.L. Zhu, "Research on the teaching of postgraduate literature retrieval course based on information literacy education," Research on Library Science, vol.274, pp.62-65, December 2011. (In Chinese)

[3] L. Wang, J.F. Li, Y. Zhong, X.L. Hu and F. wen, “The Investigation and Thoughts on the Present Situation of Literature Retrieval Course for post graduates in University Libraries of Beijing Area," Library and Information Service, vol. 59, pp. 72-78, October 2015. (In Chinese)

[4] H.T. Zhang, M.X. Shen, X.Z. Yue and Q.Y. Liu, "The Development and Countermeasures of Literature Retrieval Course,” Journal of Academic Libraries, vol.29, pp.81-85, March 2011. (In Chinese)

[5] H. Y. Wu, H.X. Zhao and L.J. Yang, "A survey of literature retrieval course in universities,” Research on Library Science, vol.287, pp.23-26, June 2012. (In Chinese)

[6] Z.Y. Ma, "Analysis on the Document Retrieval Course of University and its Countermeasures,” Agriculture Network Information, vol. 204, pp. 145-147, June 2013. (In Chinese)

[7] Q.G. Wang and C.Q. Niu, "Research on literature retrieval and the training of graduate students' innovative scientific research ability training,” Journal of Shandong Institute of Business and Technology, vol 27, pp. 116-119, March 2013. (In Chinese)

[8] C. Zhang, "Understanding and Thinking on the Innovation Ability of Graduate Students' Sci-Tech Literature Retrieval,” Innovation Science and Technology, vol. 202, pp. 85-87, December 2016. (In Chinese)

[9] F.X. Hua, "Analysis on the Compatibility of Sci-teach Novelty Retrieval Postgraduate's Literature Retrieval Course,” Journal of Library and Information Sciences in Agriculture, vol.28, pp.127-130, April 2016. (In Chinese)

[10] Z.J. Lv and D.G. Li, "An analysis on the education of literature retrieval and utilization ability of Science and Engineering graduate students," Journal of Higher Education, vol. 70, pp. 69-73, November 2017. (In Chinese) 